\title{
Hanho eli kousa
}

Kansallismuseon virkamiehenä tekemällään tutkimusmatkalla tapasi Ilmari Manninen v. 1929 Ylitorniosta piimäkauhan, jossa. oli linnunpäätä muistuttava varsi (kuva 1). Esine ei ollut vanha, mutta se kiinnitti kouliutuneen museomiehen huomiota. Se oli valmistettu v. 1924, ja tekijän oman käsityksen mukaan kauha kuvasi "haapanaa eli suorsaa": linnun päähän oli punavärillä maalattu nokan rako ja silmätkin. Kauhaa oli käytetty eräällä kesäkentällä piimän ammentamiseen suuresta saavista.

Myöhemmin Manninen totesi Kansallismuseon kokoelmiin ennestään kuuluvan kolme samantapaista kauhaa, jotka oli saatu Tammelasta, Hollolasta ja Urjalasta. Kirjallisuudesta hän tunsi näiden lisäksi vielä yhden, Kempeleen pitäjästä peräisin olevan. Havainnoistaan viehättyneenä Manninen kirjoitti Suomen Museoon tutkielman ${ }^{1}$, jossa hän yhdistää linnunpääkauhat hanhea jäljitteleviin puuvateihin, jollaisia Pohjois-Pohjanmaan murteissa nimitetään hanhoiksi eli hanhikoiksi. Edelleen U. T. Sireliukseen nojautuen'2 Manninen yhdistää hanhot ja yleensä linnunmuotoiset astiat vastaaviin skandinaavisiin esineihin ja toteaa yhtäläisyyden perustuvan myös nimeen (ruots. ölgås). Ainoan Itä-Suomesta, Suojärven pitäjästä tuntemansa esineen hän katsoo liittyvän isovenäläisten suosimiin linnunpäävateihin. Skandinaavisilla ja venäläisillä linnunmuotoisilla maljoilla Manninen arvelee olevan esihistoriallisiin suhteisiin perustuvaa yhteyttä. Sen sijaan hän jättää avoimeksi kysymyksen, millä tavoin Tyrolista ja Ranskan alpeilta Savoysta tavat-

1 I. Manninen: Suomalaiset kansatieteelliset linnunpääkauhat ja 'vadit. Suomen Museo 1929, s. $72-79$.

2 U. T. Sirelius: Suomen kansanomaista kulttuuria I, s. 344. 


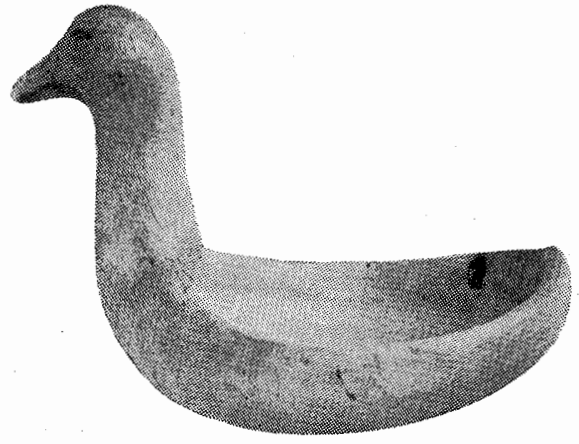

Kuva 1. Ylitorniolainen, v. 1924 tehty piimäkauha (KM 7201:215).

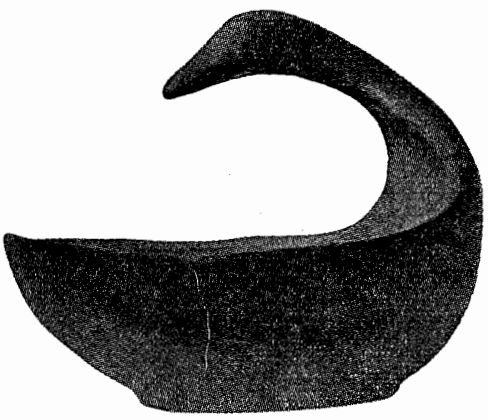

Kuva 2. "ölgâs", Jämtlanti (Fataburen 1923).

tavat linnunpääastiat liittyvät toisiinsa, "vaikkakin aate ja tarkoitus savoylaisilla suola-astioilla ja venäläisillä suolasorsilla on sama".

Pohtiessaan linnunmuotoisten astioiden syntyä Manninen päättelee, että "Pohjois-Pohjanmaan murteessa esiintyvä hanho, hanhikko on alkuaan merkinnyt juuri linnunpääastiaa, nimenomaan hanhea jäljittelevää”. Päätelmänsä tueksi hän kehittelee typologisen sarjan, kuinka "alkumuodosta" eli selvästi hanhenmuotoisesta astiasta on eri väliasteiden kautta päädytty tavalliseen kaksikorvaiseen vatiin, jossa "ei vadin korvien erilaisuudella enää voinut olla tietoista tarkoitusta - - minkä vuoksi ruvettiin pian molemmat korvat tekemään yhtäläisiksi. - - Kun ne päistään katkaistiin jyrkästi, ei niissä enää mikään muistuttanut kehityksen lähtökohtaa. Vain nimi hanho, hanhikko, siitä eräissä tapauksissa kertoi".

Usko metodiin saattaa vangita lahjakkaankin tutkijan mielikuvituksen. Tässä tapauksessa Manninen tuli luoneeksi typologisen kehityssarjan, joka ei kestä kriitillistä tarkastelua. Hänen esittämänsä typologisen kehittelyn johdosta voidaan nimittäin tehdä seuraavat huomautukset: Jos kerran linnunpäätä muistuttavat astiat palautuvat esihistorialliseen perinteeseen saakka, mikä tällöin jää kuvitellun kehitysprosessin arvoksi, kun "alkumuotoa" vastaava esine voidaan luoda uudelleen vielä 1920-luvulla? (Vrt. ylitorniolainen piimäkauha, kuva 1.) - Mistä syystä on oletettava, että sellaisella kaksikorvaisella puuastialla, jossa on kädensijat, mutta joka ei muistuta lintua, yleensä täytyisi olla lähtökohtanaan hanhen muotoinen esine? - Voidaan myös kysyä, minkä vuoksi jälkimmäi- 


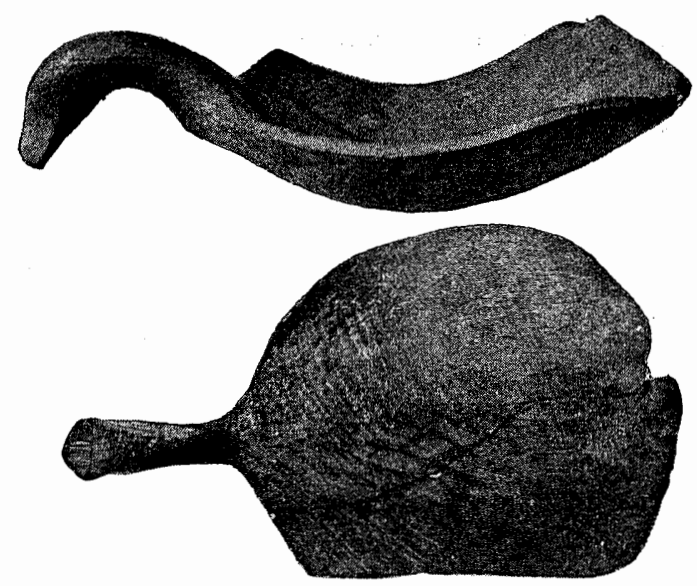

Kuva 3. Pielisjärveltä löydetty kivikautinen, sembramännystä tehty sorsanpäälusikka. Aineksensa vuoksi tuontitavaraa joko Uralilta tai KoillisVenäjältä (Aarne Europeus: Uusia kivikauden taidelöytöjä, Suomen Museo 1929).

sen, primitiivistä taideaistia tyydyttävän esineen pitäisi olla käytännön esinettä vanhempi? Eikö asetelma olisi teoreettisesti ajatellen helpompi kuvitella päinvastaiseksi eli sellaiseksi kehityssarjaksi, jonka alkupäässä olisi yksinkertainen arkiesine, taiteellisia arvoja sisältävä tulos sarjan loppupäässä?

Lähellä luontoa elävä ihminen, kuten esim. metsästäjä, tuntee eläimen anatomian niin tarkoin, että hän kykenee sitä ilmentämään vähin keinoin, kuten $\mathrm{mm}$. esihistorialliset eläimenpääaseet ja tällä vuosisadalla tehdyt siperialaiskansojen luupiirrokset osoittavat. Ymmärtääkseni pysymme turvallisella maaperällä, jos yksinkertaisesti selitämme myös linnunpääaiheisten astiaimme olevan semmoisinaan primitiivisen luonnontaiteen ilmauksia. Niille ovat sukua 1800-luvulla veistetyt eläimenpääkoristeiset länget yhtä hyvin kuin varhaiselle kivikaudelle palautuvat taideteokset. Kansantaide voi eräissä tapauksissa välittää muodon tajuamisen perinnettä aina esihistorialliselta ajalta saakka, toteaa Onni Okkonen ${ }^{3}$, ja lähellä luontoa elävä metsästäjä voi kyetä luomaan naturalistista eläintaidetta, todistaa Andreas Lindblom. 4 Tältä pohjalta ja vain tältä pohjalta

s Onni Okkonen, Suomen taiteen historia, s. 23.

4 Andreas Lindblom, Sveriges konsthistoria II, s. 635-636. 
voimme rinnastaa kivikautisen puunveistotaiteen 1900-luvun kansantaiteeseen eli esimerkiksi Pielisjärven kivikautisen sorsalusikan ylitorniolaisen Jaakko Riihisen vuonna 1924 valmistamaan hanhikkoon.

Kustaa Vilkuna on eri yhteyksissä tyhjentävästi selvittänyt Ruskon Hujalan kylän "kinkerikannun" historian ja yhdistänyt esineen Varsinais-Suomesta tunnettuihin nimipäiväkesteihin, "kousilla käymiseen", "kousien maksamiseen" ja itse kestitykseen ("juoda kousaa", "antaa kousaa"). ${ }^{5}$ Tavan levinneisyyden perusteella hän toteaa kousa sanan merkityksen laajentumisen juoma-astiasta nimipäiväpitoihin tapahtuneeksi Lounais-Suomessa. Nimipäiväkousien juontia hän pitää mahdollisesti länsimaisena peruna, mutta huomauttaa: "- se ei kuitenkaan selitä itse kousan, sarvihaarikan alkuperää, sillä. Pohjois- eikä Keski-Euroopasta emme ainakaan toistaiseksi tunne sellaisia astiatyyppejä, joista erimuotoiset kousat olisivat vaikeuksitta johdettavissa." Edelleen hän viittaa siihen, että kousaastian vanhimmasta alkuperästä voisi ehkä saada jotakin selville kohdistamalla esineellisten tutkimusten ohessa tutkimukset kousa nimen alkuperään.

Varsinaissuomalaisten nimipäiväkemujen kousa-astian alkuperä selittyy mielestäni luontevasti, jos käsitämme sen samanlaatuiseksi esineeksi, jota tarkoitetaan alussa kuvaillulla hanholla eli hanhikolla.

Kädensijoistaan linnunpääaihein koristeltuja puuastioita, kauhoja, pahkakuppeja ja puuvateja, tunnetaan myöhemmän selvitteIyn perusteella Lounais-Suomesta, Etelä-Pohjanmaalta ja PohjoisPohjanmaalta Lappiin saakka. ${ }^{6}$ Hanho (hanhikko) nimitys on tyypillisesti keskipohjalais-pohjoispohjalainen (Haapajärvi, Nivala, Ylivieska, Oulainen, Merijärvi, Vihanti, Hailuoto, Kemi, Alatornio, Simo, Tervola, Pudasjärvi, Taivalkoski, Kemijärvi, Rovaniemi, Kittilä, Sodankylä). Tavallisesti tällaista kaksikorvaista puuastiaa käytettiin ruokapöydässä piimä- ja maitoastiana (Hailuoto). Se oli veis-

5 Kustaa Vilkuna: Varsinaissuomalaisten kansanomaisesta taloudesta, s. 180-182; sama, Juhlakousat. Kalevalaseuran vuosikirja 16 (1936), s. 261--275; sama, Die Kosa, eine nordische Festschale. Acta Ethnologica 1936, s. 17-33.

6 Veera Vallinheimo: Suomalaiset linnunmuotoiset juoma-astiat. Kalevalaseuran vuosikirja 35 (1955), s. $357-367$. 


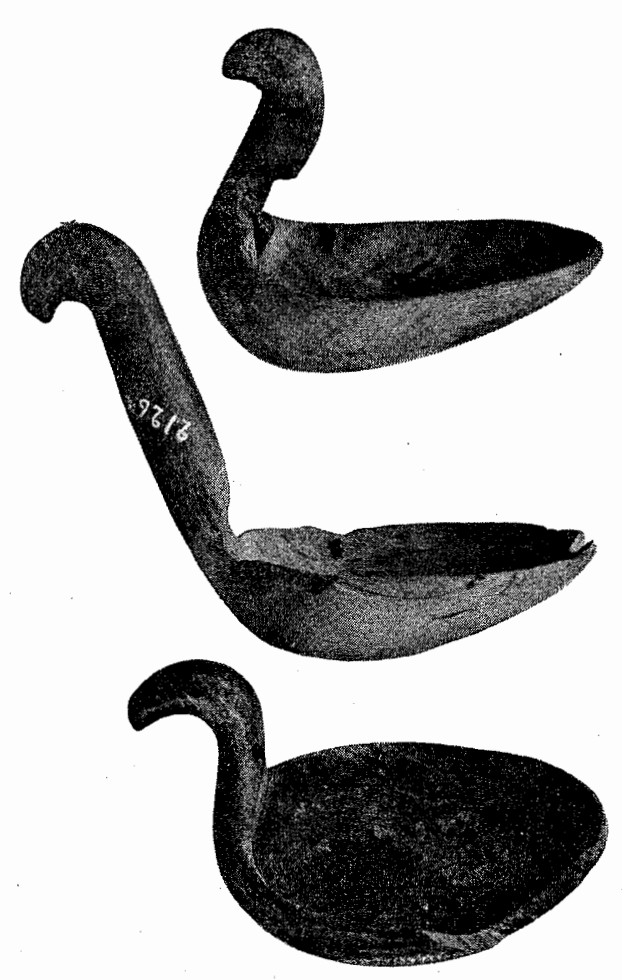

Kuva 4. Ylinnä maitokauha Tammelasta (KM B 1001), keskellä piimänaappi Hollolasta (KM B 2126), alinna maitokauha Urjalasta (KM B 2063).

tetty koivunpahkasta (Pudasjärvi, Ylivieska, Sodankylä); samanniminen astia saattoi olla yksikorvainen (Alatornio). Kittiläläinen hanho selitetään yksi- tai kaksikorvaiseksi puuastiaksi, jossa pidettiin keittoa, esim. velliä, "jota useasti vain ryypättiin hanhosta" (Laina Syrjänen 1931). Rovaniemellä "hanhoksi on sanottu semmoista puuastiaa, jolla on tuotu lihoja keittoon" (Leevi Misikangas 1935). ${ }^{7}$ Viimeksi mainitussa käytännössä, hanho lähenee lappalaisten ruoka-astiana, liha- t. kalakaukalona käyttämää latteaa puukaukaloa, kaaraa.

7 Viittaukset kansankielestä todettuihin esiintymiin perustuvat Sanakirjasäätiön aineistosta saatuihin tietoihin. 


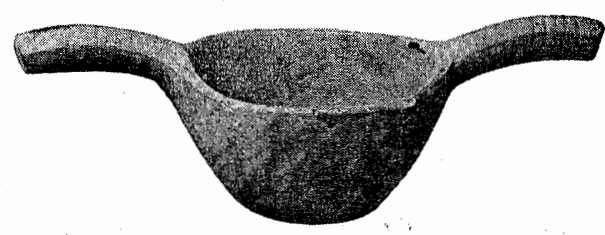

Kuva 5. "Surmjölkskoppi" Pietarsaaresta (KM B 2843).

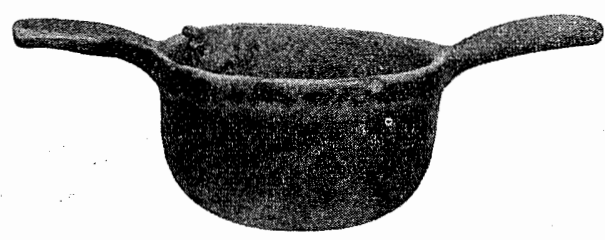

Kuva 6. Stooppi Merikarvialta (KM B 708).

Erityisen mielenkiintoista on panna merkille, että linnunmuotoisten puuastioiden perinne on jatkunut hopeisissa esineissä. Suomesta tunnetaan useitakin tämmöisiä hopea-astioita jo 1600-luvulta. Yhden sellaisen valmistajaksi tiedetään Johan Michelsson Hollst, joka toimi kultaseppänä Turussa vv. 1637-1641. Toisen valmistaja on kultaseppä Christoffer Bonstorff, joka oli ollut kultasepänkisällinä em. Johan Hollstin työpajassa Turussa ja jonka tiedetään toimineen itsenäisenä kultaseppänä Oulussa vuosinạ 1641—47. Kolmas hopeinen lintumalja tiedetään Augustus Rudolphus -nimisen oululaisen kultasepän (1694-1695) korjailemaksi. V. 1797 valmistetun "lappalaiskupin" (lappkopp) tekijä on torniolainen kultaseppä Nils Frantzleben. Viimeksi mainittu oli syntynyt Torniossa v. 1735, työskennellyt viisi vuotta Tukholmassa, elänyt elämänsä loppuvuodet Torniossa, missä hän oli 1780--90-luvuilla raatimiehenä ja kuoli v. 1802. Kaikista näistä astioista on Tyra Borg "Guldsmeder"-teoksessaan, josta yllä olevat tiedot on saatu, käyttänyt ruotsinkielistä nimitystä $k a ̊ s a .8$

Lounaissuomalaisella murrealueella voidaan kousa sanan todeta tarkoittavan seuraavanlaisia esineitä: äyskäri (Forssa), vesikuppi,

8 Tyra Borg: Guldsmeder i Finland, s. 47, 391, 378. 


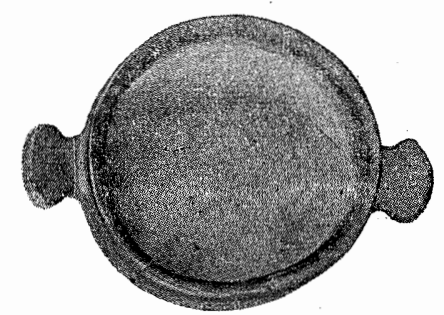

Kuva 7. Heinäniityllä särvinastiana käytetty hanha eli hanho Nivalasta (KM B 2647).

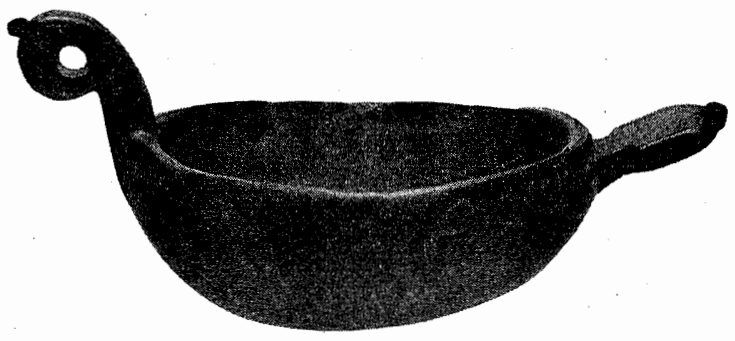

Kuva 8. "Fåglin" Närpiöstä (KM B 3534).

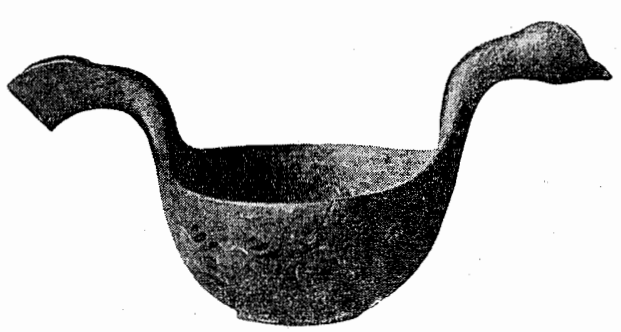

Kuva 9. Venäläinen hanho (skobkaŕ) (I. Manninen: Suomen Museo 1929 , s. 78 ).

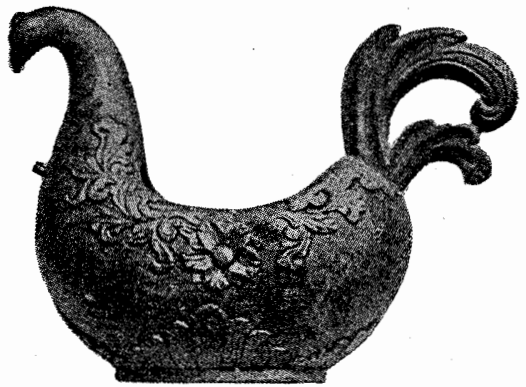

Kuva 10. Norjalainen juomamalja

(I. Manninen: Suomen Museo 1929 , s. 78$)$.

jolla pistetään vettä ämpäristä (Kalanti), piimänaappu (Nousiainen), tavallinen vedenottoastia, vesisaavin syrjällä riippuva vesinappo (Vihti). Mielenkiintoisia erikoismerkityksiä sisältää Kangasalta saatu tieto, jonka mukaan pyhäkoosa tarkoittaa juhlaruokaa ("Se Matin Rïka käy aina loppuviikolla pyhäkoosaa hajeskelemassa"). Siihen katsoen, että pohjoissuomalaisessa hanhossa pidettiin lihaa, joka on talonpoikaisessa ruokapöydässä ollut arvostettua herkkua, voimme kuvitella Kangasalan murteen "pyhäkoosan" sisältävän myös juuri hanhoa vastaavan astian merkityksen. Lammilta on muistiin merkitty lause: "Toiks sää mitien kirkonkoosaa tullessass?" Kysymys viitannee niihin hyviin antimiin, ruokaan tai juomaan, joita kousasta oli totuttu nauttimaan, ehkä tässä tapauksessa kirkonkylässä käyneeltä odotettuihin tuliaisiin. Kiinnitettäköön huomiota myös siihen, että hopeisia lintumaljoja on tietenkin valmistettu juhlatilaisuuksia, ei arkikäyttöä varten. 
Itse kousa sana on tuottanut kielentutkijoille päänvaivaa. Jo Thomsen oletti (BFB 184), että kousa, kousi sanan originaali on liettuasta venäjän kieleen lainattu sana kovš, jonka deminutiivijohdannaisesta (kóvšik) on itämurteihimme saatu vesikauhaa, ammennusvälinettä (Schöpfkelle) merkitsevä sana kousikka. Mikkola on huomauttanut (Ber. 121) kousa, koosa sanan esiintymisestä LänsiSuomessa, mikä seikka viittaisi lainan vanhuuteen ja edellyttäisi pikemmin venäläisen $o: n$ korvaamista $a$ :lla. Kalima ottaa huomioon, että sanan lounaismurteiset merkitykset 'kestit' (käydä kousilla, mennä kousille, maksaa kousia) ja 'kesteissä nautittava' (juoda kousaa, antaa kousaa) ovat helposti johdettavissa kolmannesta merkityksestä 'vesikuppi, kupponen, ammennusastia', joka sekin tavataan Lounais-Suomen murteissa. Nojautuen Vilkunaan siinä, ettei juhlakousan taiteellisesti pitkälle kehittynyt muoto todista vierasta vaikutusta, Kalima ottaa huomioon sen mahdollisuuden, että kousa on suorastaan idästä päin tullut venäjän kovš, joka on lainautunut suhteellisen myöhään hyvin monelle taholle. Mikkolan mukaan kousa, koosa juhlapäivän maljan merkityksessä on saatu ruotsin murteiden kosa sanasta, jolla on merkityksiä 'liten kopp eller tumlare helst med tvenne vågräta öron, af metall eller trä, som nyttjas i st. f. brännvinglas, skål af silfver med vågräta öron, skopa, öskar'.

Näyttää siltä, että itämurteiden kousikka on pidettävä erillään lounaismurteidemme kousasta. Thomsenin ja Kaliman selitys, että kysymyksessä on venäjän kielestä saatu lainasana, pätee edellisen, mutta ei välttämättä jälkimmäisen suhteen. Sanojen merkityskin on erilainen. Itämurteiden kousikka ei tarkoitakaan varsinaisesti astiaa, vaan kädensijallista ammennusvälinettä, esimerkiksi kauppiaan käyttämää peltistä työkalua, jolla hän käsittelee jauhoja, suoloja, ryynejä jne. 9 Tästäkin syystä itämurteiden kousikka vaikuttaa lainasanana myöhäiseltä. Uskottavalta tuntuu Mikkolan selitys, että länsimurteiden kousa, koosa on samaa juurta kuin ruotsin kosa. Myös Y. H. Toivonen on myöhemmin yhdistänyt lounaismurteiden vesikuppia, nappoa ja nimipäiväkestitystä merkitsevän kousan nykyruotsin kåsa sanaan (murt. kå, kosa, köus 'malja', 'kauha', 'nappo'). Kun kousa on Toivosen mukaan edelleen yhdistettävissä nykytans-

- Tästä on kirjoittajalle dos. Veikko Ruoppila huomauttanut. 


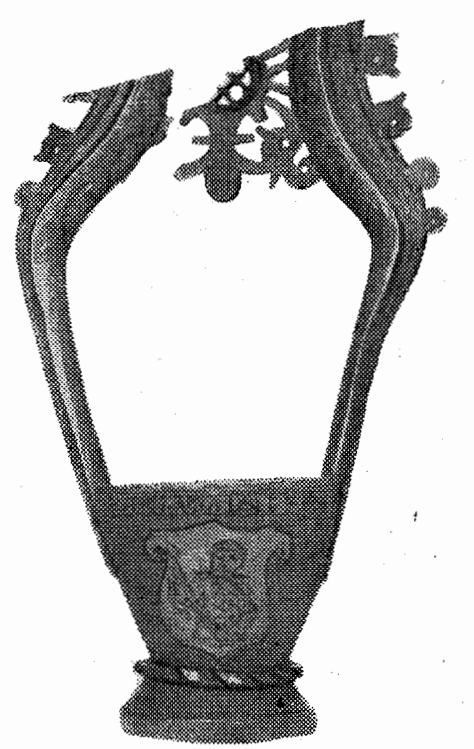

Kuva 11. Västervikin museoon kulkeutunut, suomalaisten aatelissukujen vaakunoilla koristettu juhlakousa (Kotiseutu 1951, s.51).

kan murteisiin (kous, kouse) ja se sitä tietä palautuu keskialasaksaan (kose-beker 'vieraspitojen lopussa juotu malja')10, on myös varsinaissuomalainen kousan juonti tullut juhlatapana luontevasti asetetuksi omaan kulttuurihistorialliseen yhteyteensä. Se on niitä omalaatuisia kansankulttuurin ilmentymiä, jotka liittävät VarsinaisSuomen keskieurooppalaiseen kulttuuripiiriin.

Miten tämä kysymys liittyy kuusenjuurikkaasta veistettyyn komean koristeelliseen haarikkaan ja toiselta puolen linnunmuotoiseen astiaan eli hanhoon? - Kun Olaus Magnus piirrätti "Carta marinaansa" vuonna 1539 Lounais-Suomen kohdalle tämän uljaan haarikan kuvan, hän tekstautti astian viereen sen nimeksi KosA. Sen jälkeen kun tämä erikoislaatuinen puuesine alkoi kiinnittää tutkijaimme huomiota, sitä on totuttu nimittämään kousaksi tai koosaksi. Esimerkiksi U. T. Sirelius kuitenkin toteaa ensi kerran

10 Suomen kielen etymologinen sarakirja II. 


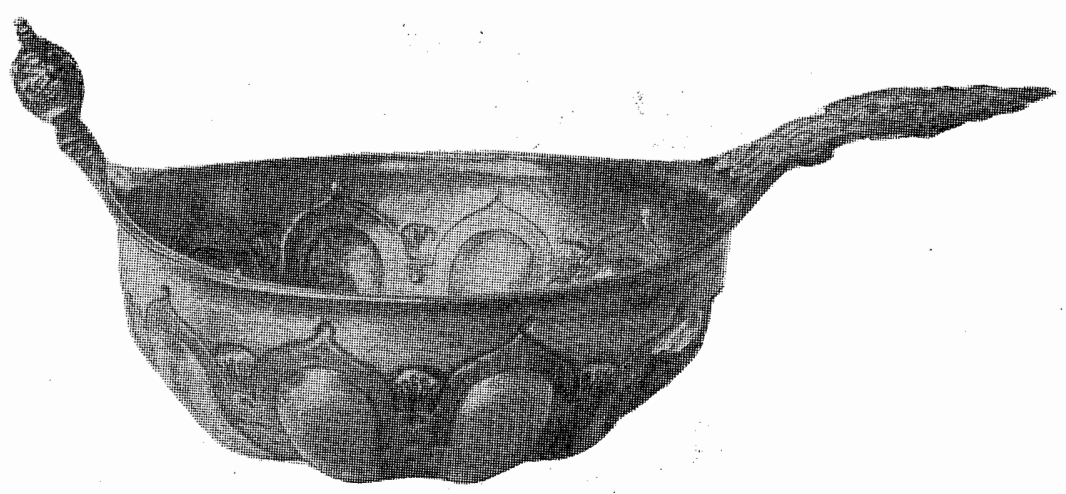

Kuva 12. Oululaisen kultasepän Christoffer Bonstorffin (1641-1647) valmistama "hopeakousa" (Tyra Borg: Guld- och silversmeder, kuva 215. Esine Kansallismuseon kok.).

Ruskon haarikasta kirjoittaessaan 11, että sitä nimitettiin paikallisen kielenkäytön mukaan "kinkeri- eli sahtikannuksi" eli "kinkerihaarikoksi". Kansanmurteista ei ole olemassa tietoja, että nimenomaan vain tämmöinen sarvihaarikka olisi ollut nimeltään kousa. Sarvihaarikoiden palautuminen vähintään 1500-luvun varsinaissuomalaiseen perinteeseen on todettu tosiasia. Mutta ne ilmeisesti edustavat paikallisen tapakulttuurin huipentumaa, jonka takana on erikoislaatuista haarikkaa vielä vanhempi, juhliin kuuluva juomaperinne. Auvo Hirsjärvi on mielenkiintoisella tavalla huomauttanut, että sarvihaarikoita on ollut muunkin tyyppisiä kuin Ruskon haarikan mallisia.12 Hän on mielestäni pätevällä tavalla osoittanut, että Vampulan kirkosta piirroksena tunnettu fragmentaarinen kousa on alkuaan ollut linnunmuotoinen yksipuinen astia. Hirsjärven kanssa en voi olla samaa mieltä siinä suhteessa, että linnunmuotoinen yksipuinen astia ja mahdollisesti keväiseen ohrankylvöjuhlaan tuorein lehvin koristeltu kaksikorvainen kimpihaarikka olisivat olleet Ruskon kinkerikannun tapaisten juhlahaarikoiden suoranaisina esikuvina. Mielestäni on toistaiseksi tyydyttävä toteamaan, että linnunmuotoinen astia eli hanho edustaa sarvihaarikoita vanhempaa kantaa. Van-

11 U. T. Sirelius: Ruskon kinkerikannu. Kalevalaseuran vuosikirja 7 (1927), s. $214-218$.

12 A. Hirsjärvi: Vakkasuomalaisen olutkoosan alkujuuria, Suomen Museo LI (1944), s. $46-63$. 
haan juhlatapaan kuulunut perinne, johon on liittynyt alkukantaiselle kansantaiteelle ominainen, kaunismuotoinen astia, on varsinaissuomalaisissa nimipäiväkousissa säilyttänyt linnunmuotoisen astian nimen nähtävästi siitä syystä, että keskieurooppalaista tapakulttuuria edustava perinne ja samalle suunnalle palautuva juomamaljaa merkitsevä kousa on kansanetymologisesti yhdistetty ruotsin hanhea merkitsevään gås sanaan. Suomen murteissa on koosa sanalla myös merkitys 'hanhi', kuten Ida Salin Siikajoelta selittää (1934). Vermlannin suomalaismurteissa kousi on merkinnyt lintua, tosin jotakin muutakin kuin hanhea: "Hanhit ne on pienempiä (kuin kousit)." Kun lisäksi ruotsissa on tapahtunut sellainen rinnakkainen kehitys, että gås merkitsee myös astiaa (esim. ölgås), tätä taustaa vasten katsottuna tuntuu varsin luonnolliselta, että pohjalaismurteissa esiintyy lounaismurteiden linnunmuotoista astiaa merkitsevän kousan kansanetymologisena käännösvastineena hanho. Kehityksen taustana on luontaisesti syntynyt, ikivanhaan perinteeseen palautuva linnunmuotoinen astia, johon liittynyttä juhlaperinnettä ilmentävät lopuksi Lapin asukkaiden suosimat, kultasepäntaidon historiaan kuuluvat hopeiset linnunmuotoiset vadit.

\section{Toivo Vuorela: Hanho und kousa}

Der Aufsatz gilt den vogelförmigen Holzgefässen, die in den finnischen Westmundarten u.a. hanho genannt werden. Diese Benennung ist eine Ableitung aus dem fi. Wort hanhi (= Gans). Der finnisehe Forscher Mlmari Manninen hat einmal zu erklären versucht, ein solches, einer Gans ähnliches Gefäss sei uralten Ursprungs und als Ergebnis typologischer Entwicklung sei daraus eine mit zwei Ohren versehene Holzschüssel entstanden, wobei nur der Vogelname an den eigentlichen Ursprung erinnere. Verf. lehnt am Anfang seines Aufsatzes diesen Versuch einer typologischen Erklärung ab und weist nach, dass es sich zwar um ein Erzeugnis alter Volkskunst mit Anknüpfungspunkten an die prähistorische Überlieferung handelt, dessen Herstellung aber noch in diesem Jahrhundert u.a. in Finnland nicht unbekannt war.

Aus Südwestfinnland kennen wir die schon von Olaus Magnus erwähnten dekorativen Trinkgefässe (eine Art Humpen), die im 15. Jahrhundert u.a. zwecks Ausfuhr nach Schweden angefertigt wurden. Kustaa Vilkuna verbindet diese "Kosa-Becker" mit den im südwestlichen Finnland üblichen Namenstagsfeiern, wobei es gebräuchlich war, die Gäste mit Getränken zu bewirten (juoda kousa $a=$ kousa trinken). In den südwestfinnischen Mundarten bedeutet kousa auch ein Gefäss ('Wasserkrug, Näpfchen, Schöpfgefäss'), das Wort wird jedoch 
nicht für künstlerisch geschnitzte Trinkgefässe gebraucht. Die Etymologie des Wortes kousa an sich ist unklar gewesen. Es ist u.a. erklärt worden, dass es entweder ein slawisches Lehnwort (< russ. kov̌̌) oder aus dem Schwedischen lierzuleiten sei (schwed. kosa). Das Wort kommt sowohl in den West-als in den Ostmundarten Finnlands vor. Verf. pflichtet der Auffassung bei, das Wort sei nur in den Ostmundarten junges russisehes Lehngut, wo auch seine Bedeutung eng umrissen ist (modernes, aus Metall hergestelltes Schöpfgefäss). Fr schliesst sich der Meinung an, zu der seines Erachtens auch der Sprachforscher Y. H. Toivonen gekommen war - dass nämlich das Wort kousa der sïdwestfinnischen Mundarten mit dem schwedischen kâsa ('Schïssel, Kelle, Napf') in Verbindung zu setzen ist, auf welchem Wege es weiterhin mit den neudänischen Mundarten (kous, kouse) und ferner mit dem Mittelniederdeutschen verknüpft werden kann (mnd. kosebeker 'am Schluss eines Gastmahles geleerter Becher'). Die endgültige Auffassung des Verf. ist, dass die auf mitteleuropäische Sittenkultur zurückgehende Trinkweise in Südwestfinnland älter sei als die dabei gebräuchlichen dekorativen Trinkgefässe aus dem 15. Jahrhundert. Die dieser Tradition entsprungenen ältesten Gefässe waren wahrscheinlich vogelförmig, wovon in der Benennung der südwestfinnischen Namenstagsfeiern eine Reminiszenz erhalten ist. Es kann sein, dass das ins Niederdeutsche zurückgehende Lehnwort später mit dem schwedischen, ebenfalls ein Gefäss bedeutenden Wort gås (= Gans) zusammenfiel. In den finnischen Westmundarten gibt es eine entsprechende Übersetzung: die Ableitung des Wortes Gans = hanhi > hanho. Der Brauch, bei festlichen Gelegenheiten vogelförmige Gefässe zu benutzen, ist bis unter die Einwohner Lapplands verbreitet gewesen, bei denen im 17. Jahrhundert hergestellte vogelförmige Silberschalen vorgefunden wurden. 